\title{
Undescended Testis in Adult: Epidemiology and Therapeutic Aspects. About 23 Cases in HKM University Teaching Hospital of Cotonou
}

\author{
Josué Avakoudjo, Fred Hodonou, Edoé Viyomé Sewa, Yannick Tandje, Jean Sossa, Magloire Yevi, \\ Isidore Gandaho, Michel Agounkpe, Gilles Natchagande
}

Urology Department of HKM National Teaching Hospital, Cotonou, Benin

Email: martini_bj@yahoo.fr

How to cite this paper: Avakoudjo, J., Hodonou, F., Sewa, E.V., Tandje, Y., Sossa, J., Yevi, M., Gandaho, I., Agounkpe, M. and Natchagande, G. (2018) Undescended Testis in Adult: Epidemiology and Therapeutic Aspects. About 23 Cases in HKM University Teaching Hospital of Cotonou. Open Journal of Urology, 8, 206-213. https://doi.org/10.4236/oju.2018.87023

Received: January 2, 2018

Accepted: July 23, 2018

Published: July 26, 2018

Copyright (C) 2018 by authors and Scientific Research Publishing Inc. This work is licensed under the Creative Commons Attribution International License (CC BY 4.0).

http://creativecommons.org/licenses/by/4.0/

\begin{abstract}
Introduction: Undescended testis is a genital pathology of pediatric age. But it is not rare that the diagnosis of this pathology is made in adults, especially in low income countries with management problems as Benin Republic. The purpose of this study was to describe the epidemiology and therapeutic aspects of this congenital malformation in adults, in HKM University Teaching Hospital of Cotonou. Material and Method: It was a retrospective, crosssectional and descriptive study, conducted from January 1, 2007 to December 31, 2016. Patient files served as data collecting support. All the patients aged 16 years and older were included in this study, treated and followed in the urology clinic department for undescended testis. Results: Twenty-three files were selected. The most represented age group was 16 to 20 years of age. The average consultation time from the observation of the anomaly was 213.6 months. The vacuity of the scrotum was the main reason for consultation. The absence of an intra-scrotal testis was the most clinical finding. The testis was found in the inguinal canal in 15 patients. Surgical re-positioning testis in scrotal location had been conducted for all patients and the open surgery was the only modality. Orchiectomy was performed in presence of atrophic testis. Any complication was reported in postoperative time. Later, two retractions of the testis and two testicular hypotrophies were seen. Semen control (spermograms) revealed persistence of azoospermia in three patients and astheno-zoospermia in another. Conclusion: Cryptorchidism is a pathology of the child but can still be seen in adults in our context. The main reason for consultation is the vacuity of scrotum but also paternity desire. Surgical lowering is the rule. In adults, its main purpose is the surveillance for the easy and early detection of a testicular tumor.
\end{abstract}




\section{Keywords}

Undescended, Testis, Adult

\section{Introduction}

Testicular dystopia or undescended testis (UDT) is a genital pathology of pediatric age and is the most common congenital malformation in the male neonates [1]. It includes cryptorchidism and ectopic testis. Its frequency in the West is around $3 \%$ to $5 \%$ in the male newborn term and a little more in the premature [2]. But it is not rare that the diagnosis of this pathology is made in adults, especially in low income countries, with problem of his management [3]. In Benin Republic, current literature to date on this pathology was related to children, and cryptorchidism was the first pediatric urological pathology [4]. The purpose of this study was to describe the epidemiology and therapeutic aspects of this congenital malformation in adults, in hospital facilities in Cotonou.

\section{Patients and Methods}

The study took place at the Clinic of Urology-Andrology of the National Center and University Teaching Hubert Koutoukou Maga Hospital (CNHU-HKM) of Cotonou. It was a retrospective, cross-sectional and descriptive study, conducted from January 1, 2007 to December 31, 2016; for a period of 10 years. Patient files served as data collecting support. All the patients aged 16 years and older were included in this study, treated and followed in the urology clinic department for undescended testis. The parameters analyzed were the age at which the abnormality was observed by the patient, the age of the patient at the diagnosis, the reasons of the consultation, the semen profile and the procedure performed as well as the surgical outcomes. Data processing was done using the usual software.

\section{Results}

Twenty-three files were selected. The mean age was $23.3 \pm 6.1$ years, with extremes of 16 and 42 years. The most represented age group was 16 to 20 years of age, as shown in Figure 1.

The average consultation time from the observation of the anomaly was 213.6 months (approximately 18 years and 9 months) with extremes of 16 and 396 months. The vacuity of the scrotum was the reason for consultation in $91.3 \%$ of patients. It was associated with intermittent inguinal pain in 16 patients $(69.6 \%)$, while $2(8.7 \%)$ consulted for a desire of paternity.

The absence of an intra-scrotal testicle was the most clinical finding: it was bilateral in 6 patients $(26.1 \%)$, right in 9 patients $(36.1 \%)$ and left in 8 patients (34.8\%), with a total of 29 undescended testes. 


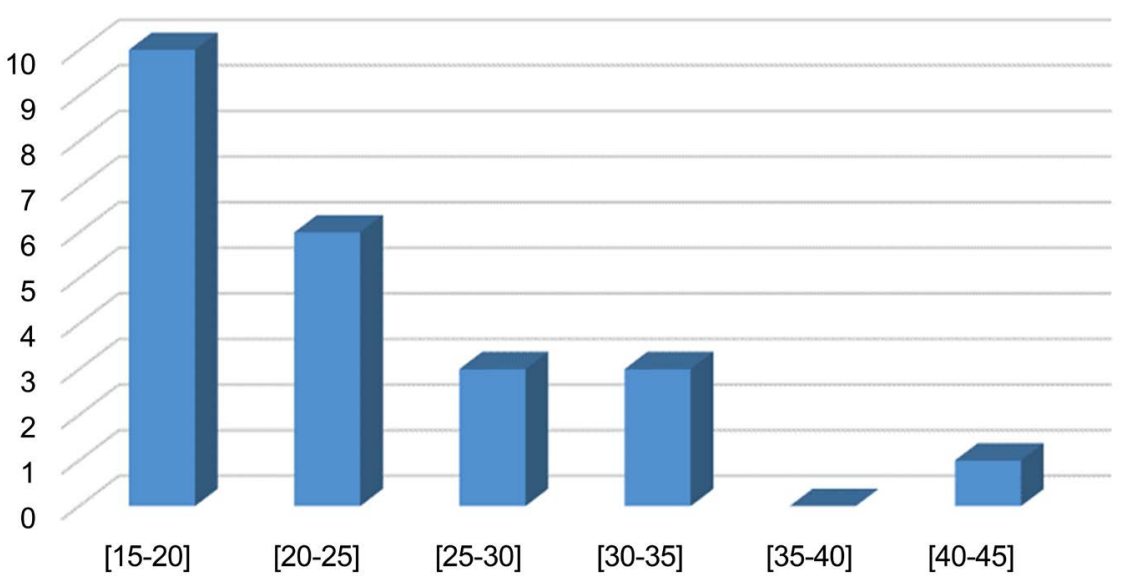

Figure 1. Distribution of patients by age group.

Persistence of peritoneal-vaginal canal was associated in 5 patients. The testicle was clinically palpated in the inguinal region in 14 patients or $60.8 \%$ of cases.

Pelvic ultrasound was performed in all patients. It had made possible to locate a likely testicular structure in 18 patients which represented $78.3 \%$ of our patients.

Eight patients had a spermogram, and four of them had azoospermia. The other four had astheno-hypospermia (2 cases), astheno-zoospermia (1 case) and astheno-theratospermia (1 case).

A hormonal assessment of testosterone and blood FSH was also performed in three patients with a result within normal ranges in all cases.

Surgical re-positioning testis in scrotal location had been conducted for all patients and the open surgery was the only modality. The approach was inguinal incision in all cases. The associated malformations were treated at the same time depending on the case. The testicle was found in the inguinal canal in 15 patients and at the superficial ring of the inguinal canal in 7 patients. The intraoperative location was consistent with what was found on ultrasound in 12 patients. Table 1 showed the per-operative locations of the undescended testis.

All patients had been operated during one procedure. The procedure towards the testis is detailed in Table 2.

Orchiectomy was performed in presence of atrophic testis. It has been bilateral in one patient.

Controlateral orchidopexy was systematically performed in patients who underwent unilateral orchiectomy. Anatomo-pathological examination of the orchiectomy specimens did not reveal any malignant testicular degenerescence.

The postoperative course was uneventful, with any complications reported in all patients. The follow-up consisted of a clinical examination of the scrotum, with an ultrasound of the testis and semen analysis for those who had done it pre-operatively. Semen control (spermograms) revealed persistence of azoospermia in three patients and astheno-zoospermia in another. 
Table 1. Intraoperative location of testis.

\begin{tabular}{ccc}
\hline Location & Number & Percentage (\%) \\
\hline Inguinal canal & 20 & 71.4 \\
External orifice of the inguinal canal & 7 & 25 \\
Testicle not founded (blind spermatic cord) & 2 & 3.6 \\
Total & 29 & 100 \\
\hline
\end{tabular}

Table 2. Intraoperative procedure toward undescended testis.

\begin{tabular}{ccc}
\hline Procedure & Number & Percentage (\%) \\
\hline $\begin{array}{c}\text { Scrotal Testis Repositioning + Orchidopexy by three-point } \\
\text { fixation }\end{array}$ & 10 & 3.1 \\
Scrotal Testis Repositioning + Orchidopexy in dartos & 9 & 33.3 \\
Orchiectomy & 8 & 29.6 \\
Total & 27 & 100 \\
\hline
\end{tabular}

Two patients had retraction of the testis in the inguinal region and testicular hypotrophy had been observed in two others.

Thirteen patients had been lost at 6 months follow-up. The other ten (10) continue their follow-up with regular check up every six months. To date, no malignant degenerescence was detected.

\section{Discussion}

The essential limit of our study is the low number of cases, and also semen examinations were not realized in all cases, in order to appreciate the real impact of UDT on the fertility. This fact did not allow us to describe the outcome of the surgery on semen parameters.

The first description of undescended testis dated back to the 18th century and theories of testis migration troubles started during the 19th century [5]. Since then, the literature has been enriched in the management of this pathology, especially in children. Observation of an undescended testis in an adult is a situation whose frequency is variously reported. Jallouli, et al. [6] in Tunisia had reported 11.26 cases per year and Fall, et al. [7] in Dakar 7 cases per year. These frequencies are beyond ours which was about two cases a year. Our frequency is certainly below reality since patients do not consult systematically for abnormalities noted but rather in case of discomfort, sometimes a possible complication. This explains the long consultation time after finding the anomaly, which was 18 years 9 months in our series. The inguinal pain experienced chronically and intermittently pushed patients to consult. In the study done by Raghavendran, et al. [8], 91\% of patients had known that they had UDT since childhood, but the consultation was done only in adulthood. The reasons given were shyness, and traditional treatments, the latter being most often the first recourse. In fact, these results demonstrate patients' ignorance of the potential severity of UDT, leading 
to their discovery, either during a routine medical examination or following a complication such as torsion of the spermatic cord [6] [9]. The emptiness of the scrotum which is the capital sign, moreover the most obvious sign should be of concern of patients as soon as it is discovered. It was the main reason for consultation in our series. It came second in the series of Fall, et al. [7] in Dakar, where infertility was the first circumstance of discovery of the undescended testis of the adult. Indeed, the mean age of patients in their series, 31.04 years, was higher than ours: patients around this age have a desire for paternity that drives them to consult.

The clinical examination is a capital time of the management of a patient who consults for UDT because it allows itself to make the diagnosis. Thus, in our work, it allowed palpating and locating the testicle in $60.8 \%$ of patients. In the series of Jeong, et al. [10], $82.4 \%$ of the undescended testis could be palpated in the inguinal region. In children, the presence of a testicle probed on the clinical examination usually exempt some complementary examinations such as ultrasound. For Ndour, et al. [11] in Senegal, the ultrasound sensitivity in this situation is low and its result does not have a great impact on the therapeutic strategy. But in adults the degenerative risks incurred by the undescended testis deserve the detection of structural abnormalities that will make opt for an orchiectomy, thus making it possible to prepare the patient psychologically before the intervention. Thus in all our patients the abdomino-pelvic ultrasound was performed and had allowed 18 patients to find a likely testicular structure. In case of non-palpable testicles, the low sensitivity and specificity of ultrasound make it unreliable and in this case, laparoscopy is recommended for testicular research. Possibly a therapeutic procedure could be performed at the same time [2] [12]. This diagnostic means was not used in any of our patients because it does not exist in the technical setup of the CNHU Cotonou.

The position of a testicle outside the scrotum has an obvious deleterious effect on its endocrine and exocrine functions. In fact, this pathology induces an alteration of Leydig cells and seminiferous tubules, which already begins between 1 and 2 years of age [13] [14]. The consequences in adulthood are the spermiological abnormalities which can take any form and manifest themselves by infertility, especially in the bilateral forms [7] [15]. These abnormalities would be more marked when the testicle is higher located [16] and indicate the need for lowering as soon as possible because these lesions are in most cases irreversible. In cases of unilateral cryptorchidism, the testicle in the normal position would not be spared by lesions, which would be due to endocrine and autoimmune phenomena [6]. These facts explain the possibility of alteration of the spermogram in these cases. Another major long-term risk of UDT is malignant degeneration as described by Niang, et al. [17] in Dakar.

Surgical treatment had been the rule in all our patients. It found the testicle in the inguinal region in $96.4 \%$ of cases. This is the most common location, as reported for $85 \%$ of patients by Jeong, et al. in his study [10]. It is recognized that 
in children, the cryptorchid testicle should be reduced between 6 months and 12 months of age, or at diagnosis after 1 year, to have the best chance of retaining testicular function [16]. In adults, however, there is no consensus. Orchidopexy has been the management for the majority of our patients. Its purpose in adults is to be able to monitor the testicles, for the early detection of abnormalities related to the development of a testicular tumor. According to Chung, et al. [18], the lesions created by UDT are irreversible, especially after puberty; the lowering is only for the surveillance of early detection of a testicular tumor, and should be done only if the patient declines the orchidectomy, which must be systematically proposed. For other authors, however, the lowering of UDT in adults could lead to an improvement in spermatogenesis and by extension fertility [6]. Thus according to Fall, et al. [7], the dogma of orchiectomy should be reconsidered because of the recent progress of different techniques of medical assistance of procreation. In our study, we performed eight orchiectomies for testis that were considered atrophic. This attitude is that advocated by Muller, et al. [19] for whom, testicular atrophy is a formal indication of orchiectomy. We believe that apart from cases of atrophic testis, the lowering could still be attempted not only to give the patient a chance of fertility, but also to preserve the body image, in regards to the fact that we do not put testicular prostheses after orchiectomy in our context, because of their unavailability.

The follow-up of an operated patient of UDT must last all his life because the treatment does not preserve the development of a testicular cancer and there is no delay for the occurrence of this one. Oh, et al. [20] described a case of cancer in a 2-year-old child, 9 months after an orchidopexy for UDT. This reflects the need for rigorous follow up when conservative treatment is chosen, moreover in adults, where the testicles have remained longer outside the scrotum.

\section{Conclusion}

Cryptorchidism is a pathology of the child but can still be seen in adults in our context. The main reason for consultation is the vacuity of scrotum but also paternity desire. Surgical lowering is the rule. In adults, its main purpose is the surveillance for the easy and early detection of a testicular tumor.

\section{Conflicts of Interest}

The authors declare no conflicts of interest regarding the publication of this paper.

\section{References}

[1] Mathers, M.J., Sperling, H., Rübben, H. and Roth, S. (2009) The Undescended Testis: Diagnosis, Treatment and Long-Term Consequences. Deutsches Ärzteblatt International, 106, 527-532. https://doi.org/10.3238/arztebl.2009.0527

[2] Merrot, T. (2009) Management of Undescended Testis. Progrès en Urologie, 19, 265-268. https://doi.org/10.1016/j.purol.2008.10.028

[3] Osifo, O.D. and Osaigbovo, E.O. (2010) Adult Patients Presenting with Undes- 
cended Testis in Awareness Poor Region. African Journal of Urology, 16, 39-45. https://doi.org/10.1007/s12301-010-0009-4

[4] Agossou-Voyeme, A.K.I., Fiogbe, M.A., Goundete, J., Hounnou, G.M. and Hodonou, R. (2013) Paediatric Urologic Pathologies at the National Teaching Hospital in Cotonou: A Etiological and Therapeutic Aspects. African Journal of Paediatric Surgery, 10, 135-139. https://doi.org/10.4103/0189-6725.115039

[5] Tackett, L.D., Patel, S.R. and Caldamone, A.A. (2007) A History of Cryptorchidism: Lessons from the Eighteenth Century. Journal of Pediatric Urology, 3, 426-432. https://doi.org/10.1016/j.jpurol.2007.07.003

[6] Jallouli, H., Fakhfakh, H., Rebai, N., Ben Abdallah, I., Trifa, M., Bahloul, A., et al. (2007) Interest of the Lowering of the Undecsended Testis in the Adult. Study of 259 Patients. Andrologie, 17, 230-235. https://doi.org/10.1007/BF03040732

[7] Fall, B., Fall, P.A., Ali, M., Diao, B., Sow, Y., Kaboré, F.A., et al. (2009) Clinical, Biological and Therapeutic Features of Adult Cryptorchidism: About 69 Cases. Andrologie, 19, 168-172.

[8] Raghavendran, M., Mandhani, A., Kumar, A., Chaudary, H., Srivastava, A., Bhandari, M., et al. (2004) Adult Cryptorchidism: Unrevealing the Cryptic Facts. Indian Journal of Surgery, 66, 160-163.

[9] Gharbi, M., Amri, N., Chambeh, W., Braiek, S. and El Kale, R. (2010) Torsions on Cryptorchid Testis. Canadian Urological Association Journal, 4, 393-396. https://doi.org/10.5489/cuaj.952

[10] Jeong, S.C., Lee, S., Ku, J.Y. and Lee, S.D. (2014) Clinical Characteristics and Treatment of Cryptorchidism in Adults: A Single Center Experience. The World Journal of Men's Health, 32, 110-115. https://doi.org/10.5534/wjmh.2014.32.2.110

[11] Ndour, O., Fall, M., Fall, A.F., Diouf, C., Ndoye, N.A., Ngom, G., et al. (2015) Epidemiological, Clinical and Therapeutic Aspects of Cryptorchidism in Children: Analysis of 123 Observations. African Journal of Urology, 21, 10-14. https://doi.org/10.1016/j.afju.2015.02.001

[12] Touiti, D., Ameur, A., Beddouch, A., Oukheira, H. and Taobane, H. (2001) Place of Laparoscopy in the Exploration and Treatment of Non Palpable Testis in Adults: about Two Observations. Annales d Urologie, 25, 353-355. https://doi.org/10.1016/S0003-4401(01)00059-6

[13] Bouya, P.A., Odzébé, A.W.S., Avala, P.P., Ondongo Atipo, M., Koutaba, E. and Cardorelle Mbika, A.I. (2012) Management of Cryptorchidism at the Brazzaville University and Hospital Center. Andrologie, 22, 108-111.

[14] Moradi, M., Karimian, B. and Moradi, A. (2011) Adult Orchidopexy: A Survey on Necessity of Intra Operative Testicular Biopsy. Nephro-Urology Monthly, 3, 196-200.

[15] Adomaitis, R., Vincel, B., Eidukaite, A., Ostaneviciute, E., Kirka, R., Bilius, V., et al. (2016) Consequences of Bilateral Cryptorchidism in Adults. Andrologia, 48, 1021-1026. https://doi.org/10.1111/and.12534

[16] Jallouli, M., Mefteh, S., Rebai, T. and Mhiri, R. (2010) Cryptorchidism: Age at the Time of Orchidopexy, Seat and Testicular Size and the Existence of Epididymal Abnormalities Influence on Fertility. Andrologie, 20, 243-246.

[17] Niang, L., Diao, B., Gueye, S.M., Fall, P.A., Moby-Mpah, H., Jalloh, M., Ndoye, A.K., et al. (2007) Cancer of Intra Abdominal Undescended Testis. Progrès en Urologie, 17, 947-949. https://doi.org/10.1016/S1166-7087(07)92394-5

[18] Chung, J.M. and Lee, S.D. (2015) Individualized Treatment Guidelines for Postpu- 
bertal Cryptochidism. The World Journal of Men's Health, 33, 161-166. https://doi.org/10.5534/wjmh.2015.33.3.161

[19] Muller, C.-O., Paye-Jaouen, A. and El Ghoneimi, A. (2012) Chirurgie du testicule non descendu. Encycl Med Chir Techniques chirurgicales-Urologie, 5, 1-8.

[20] Oh, M.M., Kim, J.W., Jong, W.K., Chae, J.Y., Yoon, C.Y., Kim, J.J., et al. (2014) Testicular Tumor Detected within 1 Year after Orchiopexy in a 2-Year-Old Boy. Urology, 83, 918-919. https://doi.org/10.1016/j.urology.2013.10.020 